\title{
Análise quali-quantitativa da vegetação e dos elementos arquitetônicos da praça Dom Assis, Jaboticabal, São Paulo ${ }^{(1)}$
}

\author{
GISELE SALES BATISTA(2), HELENA DENARDI BORELLA ${ }^{(3)}$, RENATA GIMENES(4), GUSTAVO DE NOBREGA ROMANI(5), \\ KATHIA FERNANDES LOPES PIVETTA ${ }^{(6)}$
}

\begin{abstract}
RESUMO
As praças são espaços públicos urbanos livres de edificações e que propiciam convivência e recreação para seus usuários, além de contribuírem para o embelezamento das cidades, desempenhando uma função importante no contexto urbanístico ambiental. Tendo em vista a importância das praças e as conseqüências do crescimento urbano, este trabalho teve como objetivo avaliar a situação atual e usos da Praça Dom Assis de Jaboticabal, mediante análise quali-quantitativa da vegetação e dos elementos arquitetônicos e uma pesquisa de opinião pública com a população. Foi realizado um levantamento da vegetação local (árvores, arbustos, palmeiras e herbáceas ornamentais), e uma pesquisa de opinião foi aplicada aos frequentadores da praça, em dias da semana e horários diferentes, por meio de 100 questionários com perguntas diretas aos entrevistados. A praça possui rica vegetação, com 36 espécies divididas em 18 famílias botânicas, num total de 84 indivíduos, destacando-se, entre as arbóreas, centenárias sibipirunas (Caesalpinia peltophoroides), cássia-imperial (Cassia fistula) e algumas espécies de palmeiras. Pôde-se identificar que se trata de um local muito frequentado por pessoas de diversas faixas etárias, prevalecendo idosos durante o dia e desabrigados à noite.

Concluiu-se que atualmente a praça tende mais a um bosque no meio urbano, proporcionando conforto térmico em um clima de verão tão severo como o de Jaboticabal; mas o espaço nem sempre oferece aos seus usuários mobiliários adequados e em bom estado de conservação, necessitando de readequação.
\end{abstract}

Palavras-chave: Arborização urbana, espaços públicos, paisagismo.

\section{ABSTRACT}

\section{Quali-quantitative analysis of the vegetation and architectural elements of Dom assis square in Jaboticabal, Sâo Paulo}

\begin{abstract}
Squares are urban public places without buildings that have the function to promote a healthy living of population, offering recreation and welfare in a pleasant environment. In concern of the square importance to the cities and the consequences of urban growth, this work aimed to evaluate the current vegetation and architectural elements and assess the functions of Dom Assis Square in Jaboticabal, by a quali-quantitative analysis of its vegetation and architectural elements and an opinion poll of the population. It was made a vegetation inventory (trees, shrubs, palms and ornamental herbs) and an opinion poll in different day times and week days, to 100 visitors, through a questionnaire with direct questions. Square possesses rich vegetation with 36 species into 18 botanical families in a total amount of 84 individuals, with the prevalence of centennial Caesalpinia peltophoroides individuals, Cassia fistula and some palms. It could be identified that Dom Assis Square is now enjoyed by aged people during the day and homeless people at night. It was concluded that the square actually resembles a forest in the urban environment, promoting people's welfare in a climate as severe as that of Jaboticabal, but the square does not always offer to visitors suitable furniture in good conditions.
\end{abstract}

Keywords: Urban arborization, public place, landscaping.

\footnotetext{
(1) Recebido em 10 de maio de 2013 e aceito para publicação em 30 junho de 2013.

(2) Eng. Agr., Doutoranda, Universidade Estadual Paulista - UNESP. Via de Acesso Prof. Paulo Donato Castellane, s/n - Jaboticabal (SP). Email: gismel@gmail.com

(3) Eng. Agr., Graduanda, Universidade Estadual Paulista - UNESP. Via de Acesso Prof. Paulo Donato Castellane, s/n - Jaboticabal (SP). Email: helena.denardi@gmail.com

(4) Eng. Agr., Doutoranda, Universidade Estadual Paulista - UNESP. Via de Acesso Prof. Paulo Donato Castellane, s/n - Jaboticabal (SP). Email: regimenes@ig.com.br

(5) Eng. Agr., Mestrando, Universidade Estadual Paulista - UNESP. Via de Acesso Prof. Paulo Donato Castellane, s/n - Jaboticabal (SP). Email: gustavonromani@yahoo.com.br .

(6) Profa. Dra., Universidade Estadual Paulista - UNESP. Jaboticabal, SP. kathia@fcav.unesp.br
} 


\section{INTRODUÇÃO}

As praças contribuem para o bem estar da população, pois têm funções importantes, como: paisagística, estética, de valoração da qualidade de vida local, de valorização econômica das propriedades ao entorno e arborização (SILVA et al., 2007). A população precisa perceber a relação dos vários benefícios associados à arborização urbana, como também, a ligação das árvores com a qualidade de vida (SILVA et al., 2009).

A praça é uma das representações da área verde e apresenta uma função principal de lazer; pode não ser considerada como área verde quando não possuir qualquer tipo de vegetação. Quando impermeabilizada, é denominada praças seca ou espaço duro. Quando apresenta vegetação, é denominada jardim (GUZZO, 2002).

LAMAS (1993) considera que a praça é um lugar de circulação, de encontro intencional, de permanência, de acontecimentos municipais e de manifestações da vida urbana.

Segundo PRESOTTO e ROCHA (2002), no Brasil, o planejamento paisagístico ou da paisagem não é, na verdade, considerado. Na maioria das vezes, o que temos é a destinação ou definição de uso, sem reflexão, de áreas de sobra (áreas que os projetos não incorporaram) que, para a acepção de alguns, não servem para outros usos a não ser para o que se convencionou chamar, simplesmente, de áreas para jardim, ajardinamento, áreas verdes, canteiros centrais, praças, parques, etc.

A função da praça alterou-se ao longo do tempo. $\mathrm{Na}$ antigüidade, sua função era bem mais rica de significado, não se limitando a lugar de cruzamento das vias públicas, estacionamento para automóveis ou de ponto para comércio de mercadorias as mais diversas. Esse estreitamento de sua função deu-se a partir do momento em que as estruturas logísticas dos mercados, a troca de informação e a própria informatização, aliadas ao processo de globalização, além do poder, com seus meios e seus símbolos, distanciaram-se da dimensão comunitária da coletividade e se aproximaram do privado na sua dimensão familiar, se não, ao seu isolamento individual (DE ANGELIS et al., 2005).

Além disso, os mesmos autores enfatizam o significado social da praça, como espaço da memória histórica que forneceu tanto a moldura quanto o fundo para discursos políticos e culturais sobre a cidade como local de identidade, de tradição, de saber, de autenticidade, de continuidade e estabilidade.

Tendo em vista a importância das praças e as conseqüências do crescimento urbano, o trabalho teve como objetivo a análise quali-quantitativa da arborização e elementos arquitetônicos da Praça Dom Assis de Jaboticabal, SP.

\section{MATERIAL E MÉTODOS}

O trabalho foi realizado no período de maio a outubro de 2009, na Praça Dom Assis, localizada na região central do município de Jaboticabal, São Paulo, entre o cruzamento das ruas Monteiro Lobato, Mizael de Campos e avenidas General Osório e Major Novaes, com área de $5400 \mathrm{~m}^{2}$, sendo a praça mais antiga da cidade. Foram realizadas análises de mobiliário e estruturas, conformação e vegetação. Foi considerada também a vivência na praça, abordando as diferentes manifestações humanas e os diversos usos que se conferem a esse espaço.

O presente trabalho foi dividido em três etapas, descritas a seguir: levantamento quali-quantitativo da vegetação; levantamento quali-quantitativo dos elementos arquitetônicos e pesquisa de opinião.

O levantamento quali-quantitativo da vegetação foi feito a campo mediante a contagem individual, identificação e classificação das espécies arbóreas, arbustivas, herbáceas e palmáceas com o auxílio da literatura (BRUMMITT e POWELL, 1992; LORENZI, 1992; APG II, 2003; SOUZA e LORENZI, 2008).

Os elementos arquitetônicos foram analisados com base no método proposto por DE ANGELIS et al., 2004.

Segundo os autores, o levantamento qualitativo avalia a conservação das estruturas e equipamentos por meio de notas dadas a cada tipo de elemento (Tabela 1); para isso, são dadas notas de 0 a 4 e, em seguida, empregados conceitos, como: péssimo (notas de 0 a 0,5 ), ruim (notas de 0,5 a 1,5), regular (notas de 1,5 a 2,5), bom (notas de 2,5 a 3,5 ) e ótimo (notas de 3,5 a 4,0).

Para o levantamento quantitativo dos elementos arquitetônicos, foi utilizada a ficha de cadastramento (Tabela 2), que indica a existência ou não de equipamentos e estruturas e a sua quantidade.

Para a pesquisa de opinião, aplicaram-se 100 questionários adaptados do modelo proposto por DE ANGELIS e ANGELIS NETO (2000) (Tabela 3) às pessoas presentes na Praça Dom Assis durante um período de seis meses em horários aleatórios, com a finalidade de conhecer o perfil dos frequentadores da praça e seu ponto de vista a respeito dela.

\section{RESULTADOS E DISCUSSÃO}

\section{Levantamento quali-quantitativo da vegetação}

A praça possui uma grande diversidade de espécies vegetais com 84 indivíduos distribuídos em 36 espécies pertencentes a 19 famílias botânicas (Tabela 4), onde se destacam sibipirunas (Caesalpinia peltophoroides), jerivás (Syagrus romanzoffiana), jasmim-manga (Plumeria rubra), cássia-imperial (Cassia fistula), alfeneiro-do-japão (Ligustrum lucidum var. japonicum), com frequências de $15,7 \% ; 12 \% ; 8,4 \% ; 8,4 \%$ e $6,0 \%$, respectivamente, e várias espécies frutíferas. O plantio desordenado e adensado das espécies gera um aspecto de bosque à praça.

Os valores de porcentagem de C. peltophoroides e S. romanzoffiana encontrados na Praça Dom Assis não estão de acordo com recomendação de GREY e DENEKE (1978) de valores máximos de 10 a 15\% de cada espécie na composição total de um ambiente.

Segundo dados encontrados por RIBEIRO et al. (2007) nas praças de Vinhedo (SP), a espécie de maior abundância encontrada foi o jerivá ( $S$. romanzoffiana), com abundância relativa de 31,94\% dos 764 indivíduos inventariados.

As sibipirunas ( $C$. peltophoroides) são as árvores mais encontradas na praça. A espécie é caducifólia e, segundo RIBEIRO et al. (2007), tem sido largamente empregada na arborização urbana, porém seus pequenos folíolos 
podem causar o entupimento de calhas, o que pode levar a eventuais reclamações da população, quando utilizada na arborização viária.

Em cidades onde há planejamento da arborização, a preocupação é tornar o ambiente urbano diversificado quanto às espécies empregadas, mais homogêneo $\mathrm{e}$ envolvente com a paisagem circundante (MELO e ROMANINI, 2008).

Segundo SANTAMOUR JÚNIOR (1990), a maior diversidade de espécies de árvores na paisagem urbana se faz necessária justamente para garantir o máximo de proteção contra pragas e doenças; dessa forma, recomendase não exceder mais que $10 \%$ da mesma espécie, $20 \%$ do mesmo gênero e $30 \%$ de uma família botânica. Portanto, somente para espécie $C$. peltophoroides, observou-se uma frequência relativa maior do que a recomendada pelo autor, sendo de $15,7 \%$. SAMPAIO e DE ANGELIS (2008), em levantamento arbóreo realizado na cidade de Maringá, encontraram resultados semelhantes.

Dentre as famílias encontradas, a que apresentou maior diversidade de espécies foi Myrtaceae. O mesmo foi encontrado por RABER e REBELATO (2010) em um inventário da arborização viária do Município de Colorado (RS).

Dos 84 indivíduos amostrados, oito deles são frutíferas: jaqueira (1), pitangueira (1), uvaia-gigante (1), aceroleira (3), jabuticabeira (1) e cajamanga (1). COSTA et al. (1996) alertam quanto ao fato de árvores frutíferas não serem indicadas para o plantio em vias públicas, pois frequentemente são susceptíveis a pragas, doenças e poluição.

De acordo com a Lei $n^{\circ} 2014$ de 12 de setembro de 1991 e assinada pelo então Prefeito José Giacomo Baccarin (ANDRADE, 2000), no Município de Jaboticabal, há a obrigatoriedade de plantio de uma ou mais jabuticabeiras nas praças públicas, o que pode ser verificado na Praça Dom Assis, pois ela possui um exemplar da frutífera.

\section{Levantamento quali-quantitativo elementos arquitetônicos}

As notas dadas a cada tipo de elemento arquitetônico presente na praça estão apresentadas na Tabela 5.

Existem trinta bancos em bom estado de conservação; são simples, retilíneos; feitos de cimento; não proporcionam conforto, visto que não têm encosto; estão recuados ao longo dos caminhos; a distribuição espacial é adequada, pois se encontram em áreas sombreadas e não sombreadas; há bancos para os frequentadores diários e o desenho acompanha o formato da praça. Segundo DEMATTÊ (2006), os bancos devem ser confortáveis, duráveis, de fácil limpeza e com aparência discreta, localizados parte no sol e parte na sombra, voltados para dentro e para fora da praça.

A iluminação é baixa no interior da praça e alta ao redor, em função da copa das árvores; é feita por postes bem localizados, porém há a reclamação de luzes queimadas, deixando a praça escura durante à noite. PAIVA (2001) relata que, em locais com árvores adultas, há necessidade de postes de altura mais baixa do que a copa das árvores para proporcionar uma boa iluminação. A iluminação tem a função de realçar as plantas, mantendo a beleza e constituindo um lugar agradável à noite.

Nota-se a presença de apenas três lixeiras de plástico no entorno da praça e duas de cimento próximas às mesas de jogos; embora se encontrem em bom estado de conservação, o número de lixeiras é insuficiente para o espaço, pois, segundo DEMATTÊ (2006), elas devem ter aparência discreta e estar a distâncias não maiores que cem metros umas das outras.

A lixeira deve possuir um design moderno, discreto, cuja coloração se integre ao jardim. Devem ser dispostas em postos estratégicos e devem ser em número adequado, pois dificilmente o usuário percorre uma área extensa à procura deste elemento. Lixeiras grandes, coloridas ou com propagandas prejudicam o visual da área, caracterizando poluição visual (PAIVA, 2001).

Os caminhos são pavimentados com cimento; obedecem a sua funcionalidade e segurança, visto que estão em boa conservação e permitem acesso com segurança a todos os pontos da praça. PAIVA (2001) relata que os materiais utilizados para os caminhos das praças são simples, sendo muito utilizado o cimento, em alguns casos o mosaico português, o paralelepípedo ou a cerâmica tipo Copacabana. Um piso criativo pode ser feito com cimento e com equipamentos apropriados, imitando cerâmicas. O cimento pode ser tingido, formando mosaicos ou áreas com colorações diferenciadas.

Para ABBUD (2006), o cimentado é um material de baixo custo indicado para pisos, e que pode ser colorido e receber texturas variadas.

O monumento cruzeiro é um elemento significativo que simboliza o marco inicial da cidade de Jaboticabal, sendo uma referência histórica no local; encontra-se em bom estado de conservação, mas a presença de imagens religiosas quebradas não transmite uma leitura agradável do ambiente.

No centro da praça existe uma fonte cercada por um alambrado de arame galvanizado, porém não está em funcionamento, acumulando água das chuvas, facilitando a proliferação de vetores de doenças, devendo, portanto, ser reativada ou retirada. Segundo PAIVA (2001), as fontes não são muito utilizadas nas praças atuais, principalmente em decorrência do custo e, esteticamente, estão em desuso.

O estacionamento não está em bom estado de conservação; há sombreamento para os veículos, porém não há segurança.

No local, existem pontos de ônibus e de táxi. Para o ponto de ônibus, há um abrigo; no entanto, para os taxistas, o mesmo não acontece.

Como elementos de lazer para terceira idade, verificamse mesas para jogos, as quais são muito utilizadas, merecendo melhor conservação.

Existe um parque infantil com gangorra, ponte, casinha, escorregador e balanço; os brinquedos são coloridos e feitos de ferro e madeira; embora estejam em bom estado de conservação, estão próximos da rua, requerendo maior atenção. Para PAIVA (2001), as áreas reservadas para o lazer infantil devem ser protegidas em relação às ruas circundantes, oferecendo segurança às crianças.

Para lazer gastronômico, existe um "trailer" de lanche que não combina com a estética da praça, mas tem boa localização. 
Próximo à praça, existe uma edificação institucional que é utilizada para mostra de artesanato.

Na Praça Dom Assis, não há sanitários. Segundo PAIVA (2001), a presença de sanitários em uma praça é muito controvertida; ao mesmo tempo em que caracteriza como uma área de necessidade humana básica, pela falta de conservação, torna-se uma área problemática.

Não existem telefones públicos, bebedouros, coreto, banca de revista e equipamentos para prática de exercícios físicos. Também não há identificação da Praça.

\section{Pesquisa de opinião}

Foi possível diagnosticar as características específicas dos usuários e também detectar as possibilidades e limitações da utilização do local e dos equipamentos.

É de fundamental importância ouvir a opinião da população local em relação à praça estudada. Isto porque são eles que executam atividades de lazer, manifestações, etc, que geram a dinâmica do local. As características de quem utiliza as praças são muito importantes, pois os frequentadores dão uma significação àquele local, podendo exigir determinados equipamentos e/ou possibilidades para o desenvolvimento de algumas atividades. Os não-usuários também fizeram parte da pesquisa, expressando o motivo da não-utilização da praça.

A maioria, 69\%, dos frequentadores da Praça Dom Assis tem mais de 60 anos, seguidos pela faixa etária de 41 a 60 anos (25\%). A presença de jovens é muito inferior, contando com apenas 6\% (Figura 1). Essa predominância de pessoas mais velhas, que na maioria são aposentados, se dá pela maior disponibilidade de tempo, utilizando a praça para descanso, bate-papo e jogos de baralho ou damas. Os $25 \%$ de adultos utilizam a praça com dois propósitos principais: passagem ou trabalho, tendo ao redor da praça comércio e frota de caminhões que realizam frete.

Para praças também situadas no centro da cidade, SILVA et al. (2007) e GIMENES et al. (2011) observaram maior frequência de jovens e mínima de idosos nas Praças do Bairro Centro de Teresina (PI) e na Praça Sete de Setembro de Ribeirao Preto (SP), respectivamente.

Já SILVA et al. (2008) relatam que as porcentagens de jovens e idosos foram iguais e maiores do que jovens adultos (20 - 40 anos), nas Praças Dr. Augusto Silva e Leonardo Venerando Pereira de Lavras (MG). Acredita-se que os jovens frequentem estas praças com a finalidade de entretenimento, o que não se encontra na Praça Dom Assis.

MELO e ROMANINI (2008), na Praça Ernesto Tochetto em Passo Fundo, RS, observaram frequência dos usuários bastante igualitária para as diferentes faixas etárias.

A discrepância entre a quantidade de homens e mulheres que frequentam a praça pode ser vista na Figura 2. Os homens representam $75 \%$, e as mulheres, $25 \%$, por ser a praça mais utilizada por aposentados que ficam ali o dia todo. Essa grande quantidade de homens intimida as mulheres que possivelmente poderiam utilizar a praça. No entanto, GIMENES et al. (2011) observaram que os usuários do sexo feminino representaram $61 \%$ do público total que frequenta a Praça Sete de Setembro de Ribeirao Preto (SP), provavelmente porque há muitos prédios próximos à praça, onde mulheres trabalham como empregadas domésticas, babás ou damas de companhia de idosos que por ali moram.
Com relação ao nível de escolaridade, 53\% dos usuários entrevistados possuem o ensino médio, 44\% o ensino fundamental e $3 \%$ o ensino superior (Figura 3). A porcentagem de nível superior foi bem menor em relação aos demais níveis de escolaridade; muitas pessoas entrevistadas alegaram terem tido a necessidade de parar de estudar para começar a trabalhar cedo.

Com relação à atividade ocupacional dos entrevistados, vimos que $67 \%$ são aposentados, $22 \%$ trabalham, $8 \%$ são donas de casa e 3\% desempregados (Figura 4). Os dados da Figura 4 vêm confirmar os dados da Figura 1, em que a maioria dos usuários são aposentados com mais de sessenta anos.

De todos os entrevistados, a maioria (81\%) diz ser frequentador da praça, e apenas 19\% declaram que estavam ali somente de passagem (Figura 5). A necessidade de utilização do ponto de ônibus e ou de alguns estabelecimentos comerciais contribuem para o uso deste espaço. Os aposentados, taxistas e "freteiros" são os que mais permanecem na praça.

Observa-se que 68\% dos entrevistados (Figura 6) utilizam a praça em dias de semana. Aos domingos, a praça é frequentada por $12 \%$ dos entrevistados, e aos sábados e feriados, há quase a mesma porcentagem de frequência (cerca de 10\%). Essa diminuição ocorre porque a maioria dos frequentadores utiliza o local para fins de trabalho, ou seja, permanecem somente durante período comercial e, com relação aos aposentados, eles dizem dedicar-se à vida familiar nos finais de semana, deixando de visitar o local nestes dias.

Em relação ao período de utilização, a menor frequência foi observada à noite (4\%) (Figura 7). Possivelmente isso ocorre por causa da baixa qualidade da iluminação e do grande número de andarilhos e pessoas alcoolizadas. A porcentagem de frequência da manhã e da tarde são muito próximas, sendo $45 \%$ e $51 \%$, respectivamente. Ao contrário, SILVA et al. (2008) observaram maior frequência durante a noite pelos jovens nas praças estudadas de Lavras.

Quando questionados sobre o tempo de permanência na praça, as respostas foram diversas, sendo que a maioria declarou ficar o dia todo (manhã e tarde, num total de 12 horas). Outras respostas encontradas foram: 30 minutos, 1 hora, de 3 a 4 horas, 6 horas e 8 horas diárias.

A porcentagem de pessoas que responderam à questão: “Qual o motivo que o leva a praça?" escolhendo a opção "outros" foi de 76\% (Figura 8). Para esta opção, tivemos as seguintes respostas: trabalho, passagem, jogar baralho, levar o cachorro para passear, lazer e ponto de ônibus. Apenas $12 \%$ utilizam a praça para levar crianças aos brinquedos, e $6 \%$ declararam que utilizam a praça para descansar e tomar sol.

Quando perguntado "O que você mais gosta e o que menos gosta na Praça?”, as respostas foram às seguintes:

fatores apreciativos: arborização, bancos em quantidade suficiente para todos os frequentadores, iluminação e ausência de pombas;

fatores depreciativos: andarilhos, ponto de droga, malandros, mendigos, ausência de poda e fonte isolada sem funcionamento.

As sugestões feitas para a melhoria da praça, do ponto de vista dos entrevistados, foram: 
- retirada dos andarilhos (sem-teto);

0 construção de sanitário com pessoa responsável pela sua limpeza e manutenção;

- cobertura para carros (taxistas);

- plantio de mais árvores;

- melhora na limpeza e manutenção da praça;

- reformar a fonte luminosa ou retirá-la;

- melhorar o policiamento, principalmente no período noturno;

- instalar telefones públicos;

- colocar semáforos nas esquinas, por causa da dificuldade

dos idosos em atravessar a rua;

- colocar uma cabine com chave para guardar os jogos de baralho;

- reservar um local como ponto de caminhões de frete.

Quando questionadas sobre outras praças da cidade, os entrevistados responderam que as consideram boas, porém a iluminação foi o fator de maior insatisfação, deixando a visitação no período da noite dificultada.

A opinião de $41 \%$ dos entrevistados sobre a melhoria da Praça Dom Assis ao longo dos anos foi de que a praça não teve mudanças (Figura 9), e 35\% disseram que a praça piorou. Dentre os motivos dados pelos entrevistados, as causas que contribuíram para isso foram: o nãofuncionamento da fonte; não haver mais os "charreteiros", que ali ficavam e cuidavam da praça; a desativação do banheiro e a grande quantidade de andarilhos que se instalam nela. Apenas $24 \%$ dos entrevistados acham que a praça melhorou com a colocação dos brinquedos para as crianças, com as eventuais podas e pela mudança de local da rodoviária, que servia para atrair mais marginais.

A maioria dos entrevistados (83\%) diz saber o nome da praça e $17 \%$ não souberam (Figura 10), sendo chamada também por "Joaquim Baptista". Estes dados mostram que os que realmente frequentam a praça (81\%) sabem o nome dela, o que difere dos dados encontrados por MELO e ROMANINI (2008), em que apenas 42\% dos entrevistados sabiam o nome da praça, pois nesta praça a frequência de jovens era maior que na Praça Dom Assis, e eles revelaram o desconhecimento da identidade sóciocultural que estes espaços traduzem, alheios ao registro de sua própria história, fruto do tempo e de sua evolução.

Embora a maioria tenha conhecimento do nome da praça, apenas 3\% sabiam sua história (Figura 11). Esperava-se que a porcentagem fosse maior, pois os idosos representam a maior parte da população que frequenta a praça e poderiam conhecer mais sobre a história da cidade e do local.

Muitos estudos de análise de praças brasileiras vêm sendo feitos, e uma grande diversidade de resultados tem sido encontrada. Segundo GIMENES et al. (2011), estes estudos trazem grande benefício à população local e levantam questões de ordem geral que possibilitam o avanço da discussão e, consequentemente, a readequação das praças.

Esta diversidade mostra que as praças devem ser tratadas de forma individual, respeitando as características dos usuários, e não como foi feito nas décadas de 50 e 60 , quando, por iniciativa dos governos municipais, estaduais e federal, se desenvolveu um programa de criação de praças para todas as cidades brasileiras, as quais foram criadas a partir de um projeto padrão (PIVETTA et al., 2008).

A Praça Dom Assis não é usufruída como antigamente; com o tempo, sofreu mudanças de hábitos e costumes. Se antes era o cenário de acontecimentos políticos, festividades religiosas, de atos cívicos e sociais e, nos fins de semana, servia de ponto de encontro para lazer e diversão, atualmente, a praça serve principalmente para o encontro e lazer da terceira idade durante o dia e como abrigo de indigentes durante a noite.

Constatou-se que a praça era um largo, com espaços bastante abertos, e hoje tende mais a um bosque. Pode ser considerada mais como um jardim, lembrando um fragmento da natureza no meio urbano, do que praça, que seria onde acontecem as atividades comunitárias.

Mas se o espaço não é mais tão amplo, pelo menos o sombreamento gerado pelas árvores proporciona conforto em um clima de verão severo como apresenta Jaboticabal, São Paulo.

\section{CONCLUSÃO}

A praça possui 36 espécies divididas em 18 famílias botânicas, num total de 84 indivíduos, representando mais um bosque. Pôde-se identificar que se trata de um local muito frequentado por pessoas de diversas faixas etárias, prevalecendo idosos durante o dia e desabrigados à noite; o espaço nem sempre oferece aos seus usuários mobiliário adequado e em bom estado de conservação, necessitando sua readequação.

\section{REFERÊNCIAS}

ABBUD, B. Criando paisagens - Guia de trabalho em arquitetura. 3.ed. São Paulo: SENAC, 2006. p. 1-6.

ANDRADE, D. M. Jaboticabal, jabuticabeira, jabuticaba: achegas para o conhecimento. Jaboticabal: Funep, 2000. 122p.

APG II. 2003. An update of the Angiosperm Phylogeny Group classification for the orders and families of flowering plants: APG II. Botanical Journal of the Linnean Society, London, v.141, p.399-436.

BRUMMitT, R. K., POWELL, C. E. Authors of plant names: a list of authors of scientific names of plants, with recommended standard forms of their names, including abbreviations. Richmond, Surrey: Royal Botanic Gardens Kew. 1992. 732p.

COSTA, L. M. S. A., MELlO FILHO, L. E., FARAH, I. M. C., CAMISÃO, C. Arborização das ruas do bairro de Copacabana. In: CONGRESSO BRASILEIRO SOBRE ARBORIZAÇÃO URBANA, 3., Salvador. Anais... Salvador: SBAU, 1996. p.79-88.

DE ANGELIS, B. L. D., et, G. de. Os elementos de desenho das praças de Maringá-PR. Acta Scientiarum, Maringá, v.22, n.5, p.445-1454, 2000. 
DE ANGELIS, B. L. D., CASTRO, R. M., DE ANGELIS NETO, G. Metodologia para levantamento, cadastramento, diagnóstico e avaliação de praças no Brasil. Engenharia Civil UM, Guimarães, n.20, p.57-70, 2004.

DE ANGELIS, B. L. D., et al. Avaliação das praças de Maringá, Estado do Paraná, Brasil. Acta Scientiarum, Maringá, v.27, n.4, p.629-638, 2005.

DEMATTÊ, M. E. S. P. Princípios de paisagismo. 3.ed. Jaboticabal: FUNEP, 2006. 144p.

GIMENES, R., ROMANI, G. N., BATISTA, G. S., PIVETTA, K. F. L. Interpretação do uso, do mobiliário e da arborização da Praça Sete de Setembro, Ribeirão Preto, SP. Revista Brasileira de Arborização Urbana, Piracicaba, v.6, n.3, p.22-42, 2011.

GREY, G. W., DENEKE, F. J. Urban forestry. New York: John Wiley, 1978. 279p.

GUZZO, P. Áreas verdes urbanas, 2002. Disponível em: $<$ http;//educar.sc.usp.br/biologia/prociências/areasverdes. html>. Acessado em 27 de agosto de 2009.

LAMAS, J. M. R. G. Morfologia urbana e desenho da cidade. Lisboa: Fundação Calouste Gulbenkian/Junta Nacional de Investigação Científica e Tecnológica, 1993.

LORENZI, H. Árvores brasileiras: manual de identificação e cultivo de plantas arbóreas nativas do Brasil. Nova Odessa: Plantarum, 1992, 368p.

MELO, E. F. L. Q., ROMANINI, A. Praça Ernesto Tochetto: importância da sua preservação histórica e aspectos de sua arborização. Revista da Sociedade Brasileira de Arborização Urbana, Piracicaba, v.3, n.1, p.54-72, 2008.

PAIVA, P.D. de O. Paisagismo II: macro e micropaisagismo. Lavras: UFLA/ FAEPE, 2001. 112p.

PIVETTA, K. F. L., PAIVA, P. D. O., NERI, F. C. S. Paisagismo em grandes espaços. In: PAIVA, P. D. O. Paisagismo: conceitos e aplicações. Lavras: UFLA, 2008. p.179-211.

PRESOTTO, A., ROCHA, Y. T. Planejamento e projeto paisagístico e a identificação de unidades de paisagem: o caso na lagoa do bairro Jardim América, Rio Claro,
2002. Disponível em: <http://www.geografia.fflch.usp. br/publicacoes/Geousp/Geousp13/Geousp13_Notas Felisberto_Prescotto_Rocha.htm>. Acesso em: 22 de agosto de 2009 .

RABER, A. P., REBELATO, G. S. Arborização viária do município de Colorado, RS - Brasil: análise qualiquantitativa. Revista Brasileira de Arborização Urbana, Piracicaba, v.5, n.1, p.183-199, 2010.

RIBEIRO, R. C. S., HARDER, I. C. F., TAVARES, A. R. Avaliação qualitativa e quantitativa da arborização das praças de Vinhedo, SP. Revista Brasileira de Horticultura Ornamental, Campinas, v.12, n.2, p.75-86, 2007.

SAMPAIO, A. C. F., DE ANGELIS, B. L. D. Inventário e análise da arborização de vias públicas de Maringá PR. Revista da Sociedade Brasileira de Arborização Urbana, Piracicaba, v.3, n.1, 2008, p. 37-57.

SANTAMOUR JÚNIOR, F.S. Trees for urban planting: diversity uniformity, and common sense. IN: METRIA CONFERENCE, 7., 1990, Lisle. Proceedings. Lisle: 1990. p.57-66.

SILVA, I. M., RAMOS, L. M. P., BRITO, J. S. Análise das funções das praças do bairro centro de Teresina - PI. IN: CONGRESSO DE PESQUISA E INOVAÇÃO DA REDE NORTE NORDESTE DE EDUCAÇÃO TECNOLÓGICA, 2, 2007, João Pessoa. Anais... João Pessoa, 2007.

SILVA, A. T., TAVARES, T. S., PAIVA, P. D. O., NOGUEIRA, D. A. As praças Dr. Augusto Silva e Leonardo Venerando Pereira, Lavras - MG, segundo a visão de seus frequentadores. Ciência e Agrotecnologia, Lavras, v.32, n.6, p.1701-1707, 2008.

SILVA, L. F., VOLPE-FILIK, A., LIMA, A. M. L. P., SILVA FILHO, D. F. Análise da arborização viária em bairros de Americana (SP). Revista Brasileira de Horticultura Ornamental, Campinas, v.14, n.2, p.147-158, 2009.

SOUZA, V. C., LORENZI, H. Botânica sistemática: guia ilustrado para identificação das famílias de angiospermas da flora brasileira, baseado em APG II. Nova Odessa: Instituto Plantarum de Estudos da Flora, 2008. 704p.

Tabela 1. Ficha utilizada no levantamento qualitativo dos elementos arquitetônicos na Praça Dom Assis do município de Jaboticabal, SP, 2009 
Table 1. Form used in the qualitative survey of the architectural elements in Dom Assis Square, Jaboticabal, SP, 2009

\begin{tabular}{l|l|l|}
\hline \multicolumn{1}{|c|}{ ESTRUTURAS AVALIADAS } \\
\hline 01. Bancos
\end{tabular}

Tabela 2. Ficha utilizada no levantamento quantitativo dos elementos arquitetônicos na Praça Dom Assis do município de Jaboticabal, SP, 2009

Table 2. Form used in the quantitative survey of the architectural elements in Dom Assis Square, Jaboticabal, SP, 2009

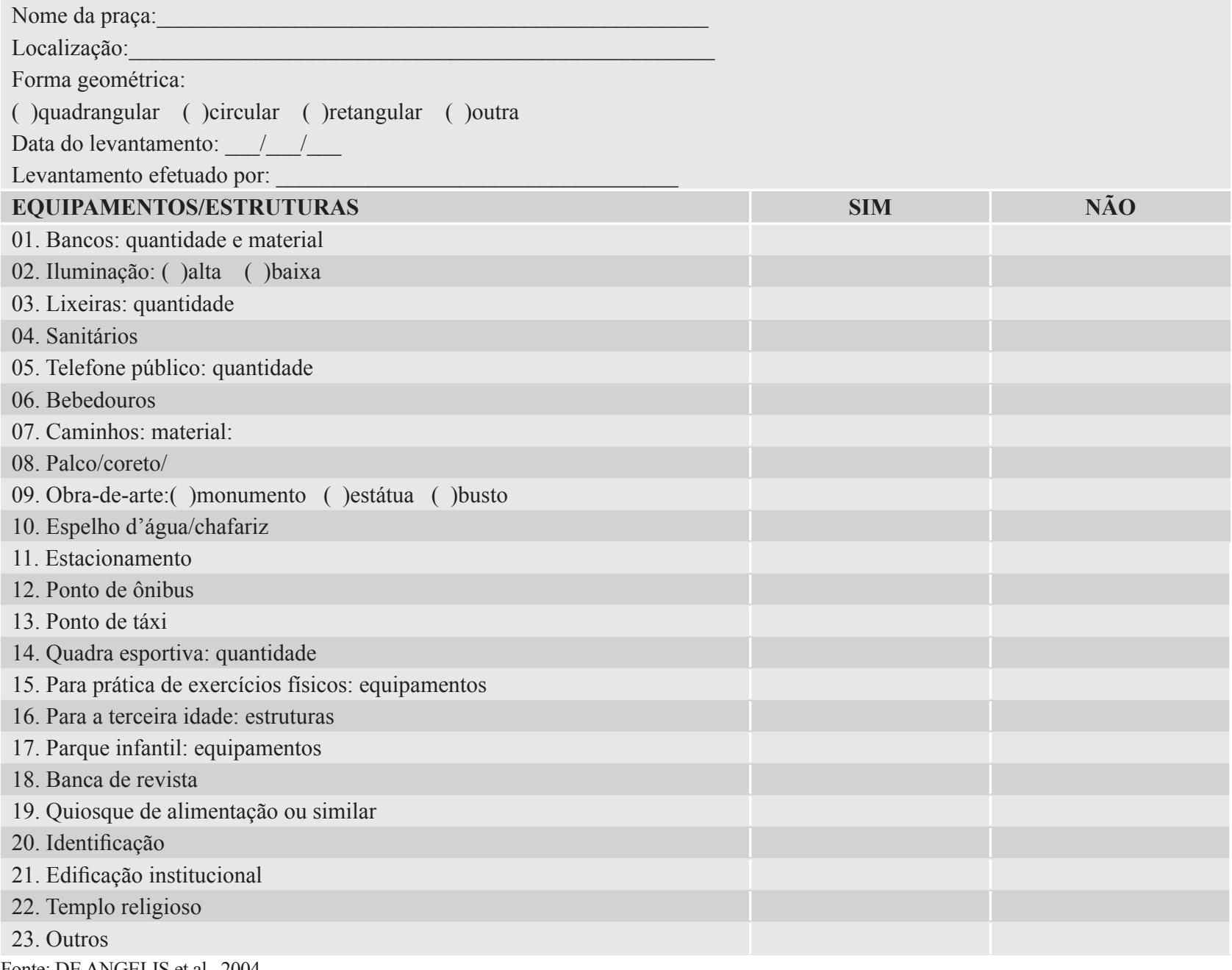

Tabela 3. Questionário utilizado na pesquisa de opinião na Praça Dom Assis do município de Jaboticabal, SP, 2009 Table 3. Questionnaire used in the opinion poll in Dom Assis Square, Jaboticabal, SP, 2009 


\section{PESQUISA DE OPINIÃO}
1. Idade
() 0 - 20 ( )21 - 40 ( ) 41 - 60 ( )Mais de 60

\section{Sexo}

()M ( )F

\section{Nível Escolar}

()Fundamental ( )Médio ( )Superior
4. Atividade Ocupacional
( )Trabalhador ( )Estudante ( )Aposentado ( )Dona de casa ( )Desempregado

5. Você frequenta essa praça?

( )Sim ( )Não - Por quê?

6. Quais dias da semana você vai à praça?

( )Durante a semana ( )Sábado ( )Domingo ( )Feriado

7. Em que período você vai com mais frequência à praça?

( )Manhã ( )Tarde ( )Noite

8. Em média, qual é o seu tempo de permanência na praça?

9. Qual (is) o motivo que o leva à uma praça?

( )Tomar Sol ( )Caminhar ( )Ler ( )Levar Criança ( )Descansar ( )Praticar esportes ( )Outros

10. O que você mais gosta e o que menos gosta na(s) praça(s) que frequenta?

11. O que você acha que é necessário melhorar nas praças que frequenta?

12. Qual é a sua opinião sobre as praças da sua cidade?

13. Qual a mudança na infra-estrutura da praça, no decorrer dos anos? (melhorou, piorou)

\section{Sabe o nome desta praça?}

15. Sabe a história desta praça?

Fonte: Adaptado de DE ANGELIS e ANGELIS NETO (2000).

Tabela 4. Levantamento da vegetação na Praça Dom Assis, Jaboticabal, SP, 2009

Table 4. Survery of vegetation in Dom Assis Square, Jaboticabal, SP, 2009 


\begin{tabular}{|c|c|c|c|c|c|}
\hline CÓD. & NOME CIENTÍFICO & NOME COMUM & FAMÍLIA & NI & FR $(\%)$ \\
\hline $\mathrm{Pa}$ & Acrocomia aculeata & Macaúba & Arecaceae & 2 & 2,4 \\
\hline Av & Araucaria heterophylla & Araucária & Araucariaceae & 1 & 1,2 \\
\hline Av & Artocarpus heterophyllus & Jaqueira & Moraceae & 1 & 1,2 \\
\hline $\mathrm{Ar}$ & Blepharocalyx salicifolius & Murta & Myrtaceae & 1 & 1,2 \\
\hline Av & Caesalpinia peltophoroides & Sibipiruna & Fabaceae & 13 & 15,7 \\
\hline Av & Terminalia catappa & Sete-copas & Combretaceae & 4 & 4,8 \\
\hline $\mathrm{Pa}$ & Caryota urens & Palmeira-rabo-de-peixe & Arecaceae & 1 & 1,2 \\
\hline Av & Cassia fistula & Cássia-imperial & Fabaceae & 7 & 8,4 \\
\hline Av & Casuarina equisetifolia & Casuarina & Casuarinaceae & 1 & 1,2 \\
\hline Av & Delonix regia & Flamboyant & Fabaceae & 3 & 3,6 \\
\hline $\mathrm{Ar}$ & Dracena marginata hort. & Dracena & Liliaceae & 1 & 1,2 \\
\hline Av & Enterolobium contortisiliquum & Tamboril & Fabaceae & 1 & 1,2 \\
\hline $\mathrm{Ar}$ & Eugenia uniflora & Pitangueira & Myrtaceae & 1 & 1,2 \\
\hline Av & Eugenia uvalha & Uvaia-gigante & Myrtaceae & 1 & 1,2 \\
\hline Av & Faurea saligna & Mutango & Proteaceae & 1 & 1,2 \\
\hline Av & Ficus carica & Figueira & Moraceae & 2 & 2,4 \\
\hline Av & Ficus macrophylla & Fícus & Moraceae & 1 & 1,2 \\
\hline $\mathrm{Pa}$ & Grevillea robusta & Grevílea-robusta & Proteaceae & 1 & 1,2 \\
\hline Av & Guarea guidonia & Marinheiro & Meliaceae & 1 & 1,2 \\
\hline $\mathrm{Ar}$ & Houvenia dulcis & Uva-japonesa & Rhamnaceae & 1 & 1,2 \\
\hline Av & Hymenaea courbaril var.stilbocarpa & Jatobá & Fabaceae & 1 & 1,2 \\
\hline Av & Ligustrum lucidum var.japonicum & Alfeneiro-do-japão & Oleaceae & 5 & 6 \\
\hline Av & Malpighia emarginata & Aceroleira & Malpighiaceae & 3 & 3,6 \\
\hline $\mathrm{He}$ & Melia azedarach & Santa-bárbara & Anacardiaceae & 1 & 1,2 \\
\hline $\mathrm{Ar}$ & Mussaenda erythrophylla & Mussaenda & Rubiaceae & 1 & 1,2 \\
\hline Av & Myrciaria cauliflora & Jabuticabeira & Myrtaceae & 1 & 1,2 \\
\hline Av & Nectandra megapotamica & Canelinha & Lauraceae & 1 & 1,2 \\
\hline $\mathrm{Pa}$ & Phoenix reclinata Jacq. & Tamareira-do-senegal & Arecaceae & 1 & 1,2 \\
\hline $\mathrm{Ar}$ & Plumeria rubra & Jasmim-manga & Apocynaceae & 7 & 8,4 \\
\hline Av & Poecilanthe parviflora & Coração-negro & Fabaceae & 1 & 1,2 \\
\hline Av & Sapindus saponaria & Sabão-de-soldado & Sapindaceae & 1 & 1,2 \\
\hline Av & Spondias cytherea & Cajamanga & Anacardiaceae & 1 & 1,2 \\
\hline $\mathrm{Pa}$ & Syagrus romanzoffiana & Jerivá & Arecaceae & 10 & 12 \\
\hline Av & Handroanthus impetiginosus & Ipê-roxo & Bignoniaceae & 1 & 1,2 \\
\hline $\mathrm{Av}$ & Tipuana tipu & Tipuana & Fabaceae & 3 & 3,6 \\
\hline $\mathrm{He}$ & Tynanthus fasciculatus & Cipó-cravo & Bignoniaceae & 1 & 1,2 \\
\hline
\end{tabular}

* $\mathrm{Av}$ = árvore; $\mathrm{Pa}$ = palmeira; $\mathrm{He}=$ herbácea; $\mathrm{Ar}$ = arbusto; $\mathrm{NI}$ = número de indivíduos; $\mathrm{FR}$ = freqüência relativa. 


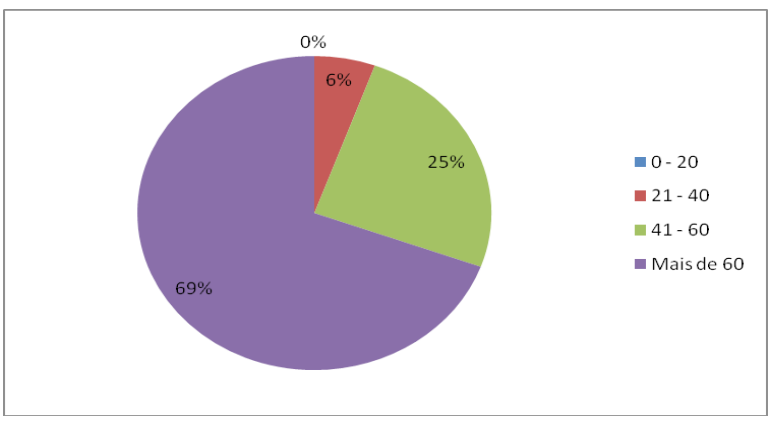

Figura 1. Frequência de usuários segundo a faixa etária na Praça Dom Assis, Jaboticabal, SP, 2009

Figure 1. Frequency of users by age in Dom Assis Square, Jaboticabal, SP, 2009

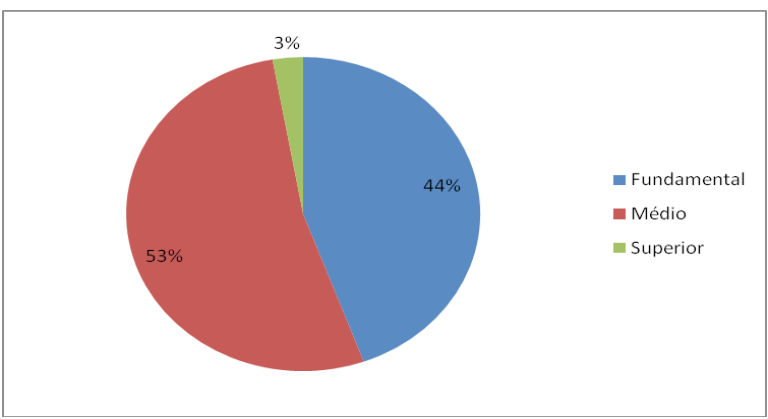

Figura 3. Frequência de usuários segundo o nível de escolaridade na Praça Dom Assis, Jaboticabal, SP, 2009 Figure 3. Frequency of users by education level in Dom Assis Square, Jaboticabal, SP, 2009

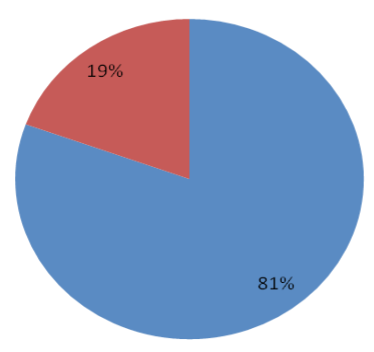

- $\operatorname{\text {Nim}}$

Figura 5. Frequência de usuários na Praça Dom Assis, Jaboticabal, SP, 2009

Figure 5. Frequency of users in Dom Assis Square, Jaboticabal, SP, 2009

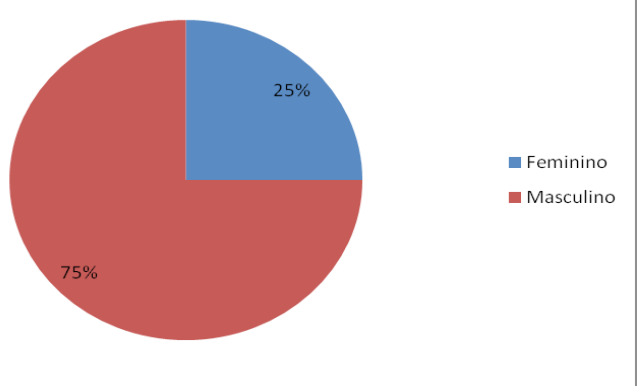

Figura 2. Frequência de usuários segundo o sexo na Praça Dom Assis, Jaboticabal, SP, 2009

Figure 2. Frequency of users by gender in Dom Assis Square, Jaboticabal, SP, 2009

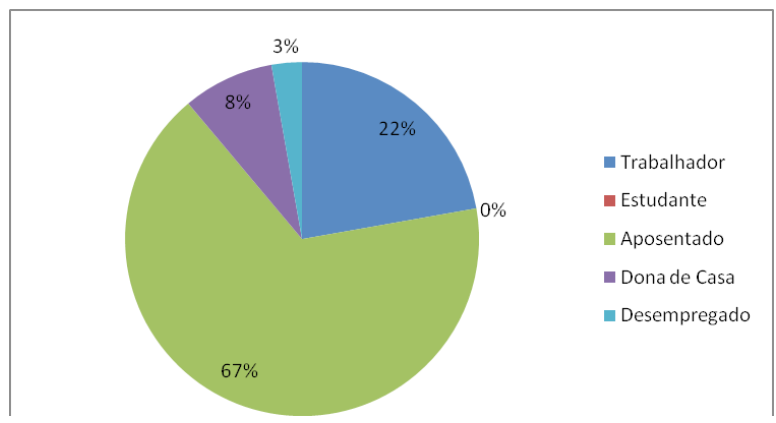

Figura 4. Frequência de usuários segundo a atividade ocupacional na Praça Dom Assis, Jaboticabal, SP, 2009 Figure 4. Frequency of users by occupational activity in Dom Assis Square, Jaboticabal, SP, 2009

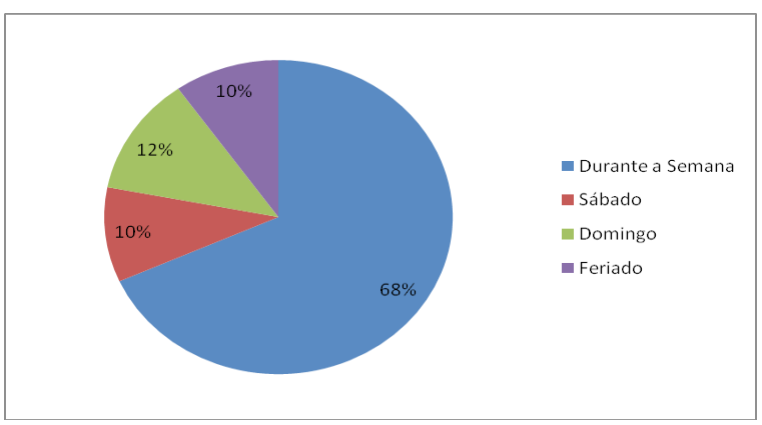

Figura 6. Frequência de usuários em relação aos dias da semana na Praça Dom Assis, Jaboticabal, SP, 2009 Figure 6. Frequency of users during the week days in Dom Assis Square, Jaboticabal, SP, 2009 


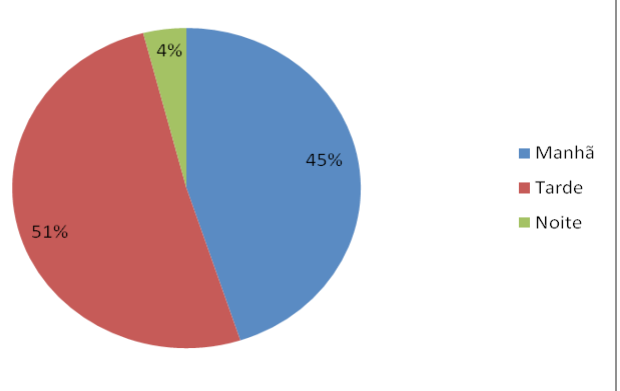

Figura 7. Período de frequência de usuários na Praça Dom Assis, Jaboticabal, SP, 2009

Figure 7. Period of users frequency in Dom Assis Square, Jaboticabal, SP, 2009

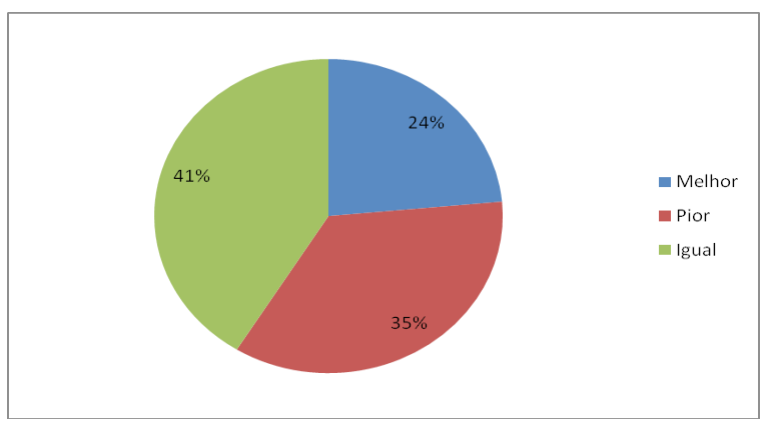

Figura 9. Opinião dos entrevistados segundo a mudança na infra-estrutura no decorrer dos anos na

Praça Dom Assis, Jaboticabal, SP, 2009

Figure 9. Opinion of respondents according to the change in the infrastructure over the years in

Dom Assis Square, Jaboticabal, SP, 2009

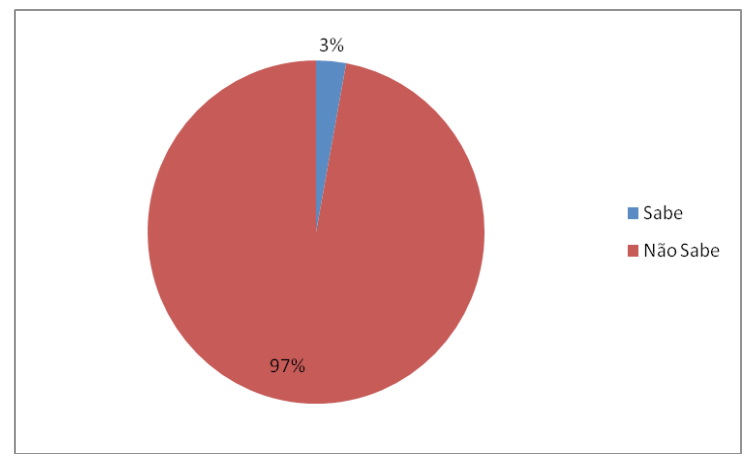

Figura 11. Conhecimento dos entrevistados sobre a história da Praça Dom Assis, Jaboticabal, SP, 2009

Figure 11. Knowledge of respondents about the history of Dom Assis Square, Jaboticabal, SP, 2009

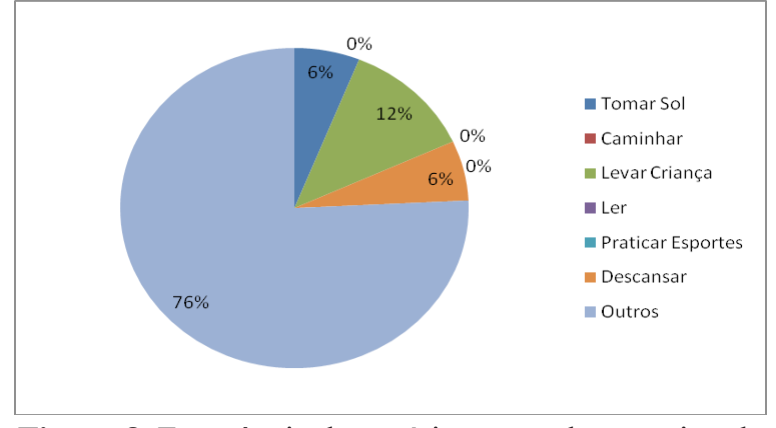

Figura 8. Frequência de usuários segundo o motivo de utilização na Praça Dom Assis, Jaboticabal, SP, 2009

Figure 8. Frequency of users by the reason for use in Dom Assis Square, Jaboticabal, SP, 2009

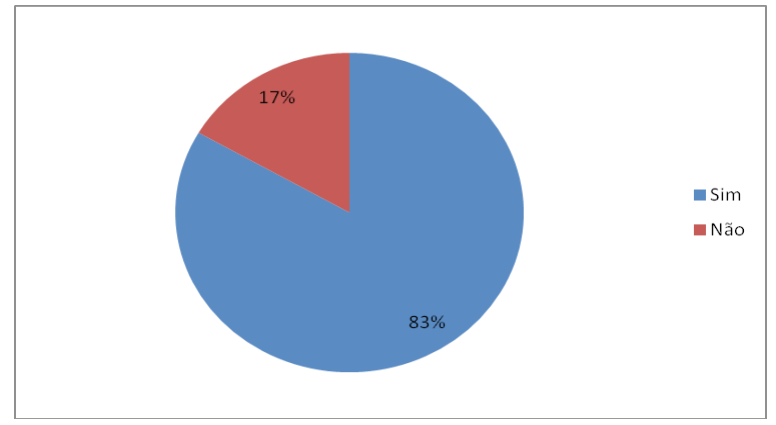

Figura 10. Resultado da pergunta "Você sabe o nome desta praça?", Jaboticabal, SP, 2009

Figure 10. Results of the question "Do you know the name of this square?”, Jaboticabal, SP, 2009 
Tabela 5. Avaliação dos elementos arquitetônicos na Praça Dom Assis do município de Jaboticabal, SP, 2009 Table 5. Assessment of the architectural elements in Dom Assis Square, Jaboticabal, SP, 2009

ESTRUTURAS AVALIADAS

NOTAS

01. Bancos

02. Iluminação alta

2,0

03. Iluminação baixa

04. Lixeiras

05. Sanitários

06. Telefone público

07. Bebedouros

08. Piso

09. (X) monumento ( ) estátua ( ) busto

11. Espelho d'água/chafariz/ fonte

12. Estacionamento

13. Ponto de ônibus

14. Ponto de táxi

15. Parque infantil

16. Banca de revista

17. Quiosque para alimentação e/ou similar

18. Vegetação

19. Manutenção das estruturas físicas

20. Limpeza

21. Conforto térmico

Fonte: adaptado de DE ANGELIS et al., 2004.
4,0

4,0

1,0

-...

1,5

0,5

2,0

2,5

1,5

3,0

2,0

3,5

0,5

0,5

4,0 